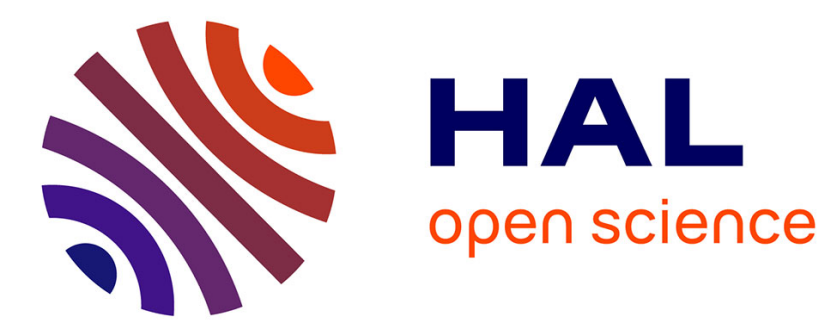

\title{
Toxoplasmosis in Rodents: Ecological Survey and First Evidences in Thailand.
}

Sathaporn Jittapalapong, Nachai Sarataphan, Soichi Maruyama, Jean-Pierre Hugot, Serge Morand, Vincent Herbreteau

\section{- To cite this version:}

Sathaporn Jittapalapong, Nachai Sarataphan, Soichi Maruyama, Jean-Pierre Hugot, Serge Morand, et al.. Toxoplasmosis in Rodents: Ecological Survey and First Evidences in Thailand.. Vector-Borne and Zoonotic Diseases, 2010, 11 (3), pp.231-237. 10.1089/vbz.2009.0238 . hal-00545606v2

\section{HAL Id: hal-00545606 \\ https://hal.science/hal-00545606v2}

Submitted on 4 Jul 2012

HAL is a multi-disciplinary open access archive for the deposit and dissemination of scientific research documents, whether they are published or not. The documents may come from teaching and research institutions in France or abroad, or from public or private research centers.
L'archive ouverte pluridisciplinaire HAL, est destinée au dépôt et à la diffusion de documents scientifiques de niveau recherche, publiés ou non, émanant des établissements d'enseignement et de recherche français ou étrangers, des laboratoires publics ou privés. 


\title{
Toxoplasmosis in Rodents: Ecological Survey and First Evidences in Thailand
}

\author{
Sathaporn Jittapalapong,, Nachai Sarataphan, ${ }^{2}$ Soichi Maruyama, Jean-Pierre Hugot, ${ }^{4}$ \\ Serge Morand, ${ }^{5,6}$ and Vincent Herbreteau ${ }^{6,7}$
}

\begin{abstract}
Domestic and wild rodents known as the most abundant and diversified order of mammals have a key role in the ecological food chain and also in the transmission of parasites and pathogens to other animals. While foraging on the ground, they can get infected by Toxoplasma gondii, a protozoan parasite, which is the causative agent of toxoplasmosis. Therefore, they serve as intermediate hosts of T. gondii and can transmit it to their predators. To assess their role in the maintenance of $T$. gondii lifecycle in Thailand, we sampled rodents in a range of biotopes representative of the high biodiversity and conducted a serological survey with latex agglutination test to detect anti-T. gondii antibodies. Overall, 21 of $461(4.6 \%)$ rodents had diagnostically significant antibody titers (cutoff, 1:64). Every species with at least 37 individuals captured tested positive, confirming the wide range of potential mammalian hosts of toxoplasmosis. None of the ecological traits (sex, maturity, morphology, season, or habitat) was found significant to predict the susceptibility to $T$. gondii both univariately and in a multivariate analysis. However, high prevalences were reported in either forested or anthropized areas. This survey constitutes the first confirmed serological investigation of $T$. gondii in rodents in Thailand. The rarity of both domestic and wild felids in Thailand emphasizes the importance of rodents in maintaining T. gondii, and questions the involvement of other carnivores in the life cycle.
\end{abstract}

Key Words: Ecology—Murinae—Rattus—Rodent—T. gondii—Toxoplasmosis.

\section{Introduction}

$\mathbf{M}$ ORE THAN 100 YEARS AGO, a protozoan parasite, Toxoplasma gondii, was described from an African rodent, Ctenodactylus gundi (Nicolle and Manceaux 1908), and simultaneously from a rabbit in Brasil (Splendore 1908). T. gondii is the unique species in the genus Toxoplasma of the Coccidian family and has the widest host range and distribution, being potentially carried by any warm-blooded animal (mammals and birds), with cats as definitive hosts (Tenter et al. 2000, Dubey 2008). As a consequence, toxoplasmosis is one of the most common parasitic diseases worldwide, probably infecting about one-third of humans (Tenter et al.
2000, Kim and Weiss 2008). T. gondii is mainly transmitted congenitally or by ingestion either of bradizoites in infected tissues or of oocysts spread in the environment. The risk of infection by ingestion for rodents is related to the complexity of environmental factors that determine the presence of other mammals, especially felids and oocysts. Climate also conditions the dispersal, density, and survival of oocysts, because their resistance depends on humidity and temperature (Dubey and Frenkel 1998).

Researches on rodents have been limited even if they might play a significant role in the epidemiology of toxoplasmosis, by being potential intermediate hosts before the transmission to pigs, dogs, or cats (Dubey and Frenkel 1998). A major

\footnotetext{
${ }^{1}$ Department of Parasitology, Faculty of Veterinary Medicine, Kasetsart University, Bangkok, Thailand.

${ }^{2}$ Bureau of Biotechnology for Livestock Production, Department of Livestock Development, Ministry of Agriculture and Cooperatives, Pathumthani, Thailand.

${ }^{3}$ Laboratory of Veterinary Public Health, Department of Veterinary Medicine, College of Bioresource Sciences, Nihon University, Kanagawa, Japan.

${ }^{4}$ Muséum National d'Histoire Naturelle, OSEB, Paris, France.

${ }^{5}$ CNRS-UM2, Institut des Sciences de l'Evolution (ISEM), Université Montpellier 2, Montpellier, France.

${ }^{6}$ CIRAD, UR Animal et Gestion Intégrée des Risques (AGIRs), Campus International de Baillarguet, Montpellier, France

${ }^{7}$ IRD Research Unit 178, Faculty of Sciences, Center for Vectors and Vector-borne Diseases, Mahidol University, Bangkok, Thailand.
} 
review of this work was realized by Dubey and Frenkel (1998), who analyzed investigations of T. gondii in rats worldwide and proposed interesting information about the implication of rats in the life cycle of this parasite. The authors report a low average prevalence of antibodies to $T$. gondii in rats, generally under $5 \%-10 \%$, and also correctly point out the difficulties to compare various serological screenings conducted with different methods. Nevertheless, we considered this review to be a fundamental source of information about rodent species occurring also in Thailand, according to the reference book Mammal Species of the World (Carleton and Musser 2005).

Further, the implication of rodents in the life cycle of T. gondii remains misunderstood when considering the transmission between different hosts, as well as the influence of ecological factors (Tenter et al. 2000, Kim and Weiss 2008). Few studies have considered how ecological traits of the animal host can influence the seroprevalence of toxoplasmosis. In the Philippines, Salibay and Claveria (2005) found no relationship between $T$. gondii prevalence and rodent species (Rattus norvegicus and Rattus mindanensis) and no correlation between the prevalences in their three collection sites. They also reported a higher but not statistically significant seroprevalence in males (Salibay and Claveria 2005). In the United States, Dabritz et al. (2008) found no relationship between T. gondii prevalence and the association of rodent habitat with water. Nevertheless, they could associate a greater distance to houses $(>200 \mathrm{~m})$ and the maturity (adult) with a higher prevalence (Dabritz et al. 2008). In French Guyana, de Thoisy et al. found that terrestrial mammals are significantly more exposed to $T$. gondii than other mammals and noticed discordant results for the agouti and the acouchy, because of their feeding behavior (they are granivorous and highly selective foragers). They finally recommended further analysis regarding the influence of habitat and behavior (de Thoisy et al. 2003).

In Thailand, where toxoplasmosis has never been investigated in rodents, recent studies have shown widespread cases of infection in humans (Maruyama et al. 2000), dogs and cats (Jittapalapong et al. 2007), swine (Thiptara et al. 2006), goats (Jittapalapong et al. 2005), elephants (Tuntasuvan et al. 2001), and tigers (Thiangtum et al. 2006). Therefore, this study was first designed to determine the presence and prevalence of T. gondii in wild rodents in Thailand and then to enlighten from an ecological point of view their importance in the transmission of this parasite either to other animals or to humans.

\section{Materials and Methods}

\section{Study sites and animal trapping}

From 2003 to 2006, rodents were captured in 13 provinces throughout Thailand to study their implication in the transmission of different pathogens to humans (Fig. 1). Trapping locations were chosen to sample animals in a range of biotopes representative of the high biodiversity peculiar to Thailand and Southeast Asia. In each site, 20 locally made cages were used during five nights to catch animals alive. This field work was repeated during the dry and wet seasons. Geographical coordinates of the trapping places were systematically recorded. Trapping and processing were conducted according to established safety recommendations (Mills et al. 1995). Animals were collected early in the morn-

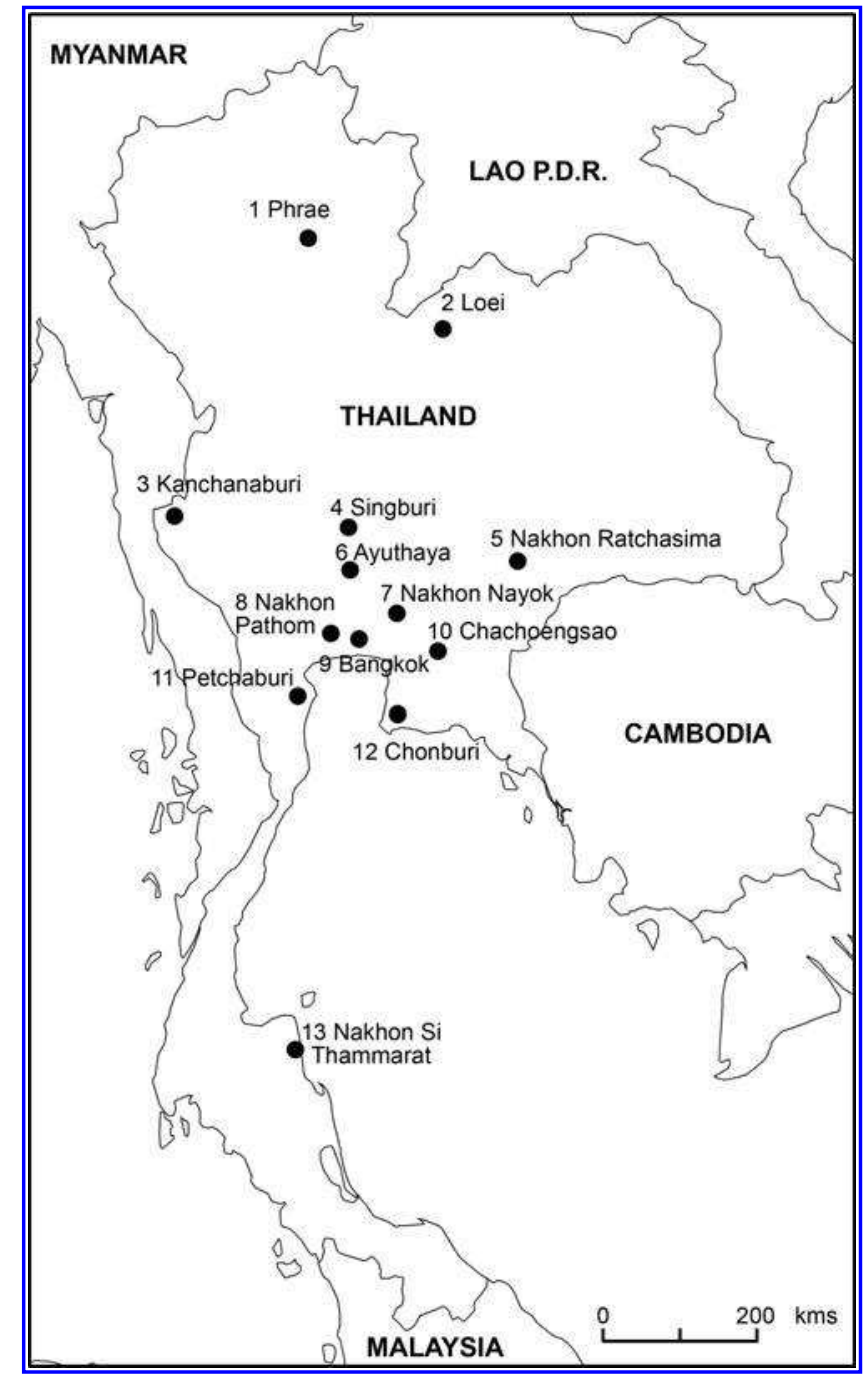

FIG. 1. Location of sampling sites in 13 Thai provinces.

ing and transferred to a field laboratory, where they were dissected to collect organs for different studies of rodentborne pathogens. Blood was collected by cardiac puncture and later separated by centrifugation. Serum samples were stored in liquid nitrogen and then kept in $-80^{\circ} \mathrm{C}$ freezer before testing. Species were identified based on morphological criteria following regional taxonomic identification keys (Askins 1988, Marshall 1988, Corbet and Hill 1992, Aplin et al. 2003).

\section{Serological assays}

T. gondii antibodies were detected using a latex agglutination test kit (Toxocheck-MT; Eiken Chemical Co., Ltd). This test has been evaluated as a suitable screening serological method to assess the presence of toxoplasmosis in all species of animals with a high sensitivity and specificity (Mazumder et al. 1988, Tilahun et al. 1998). The manufacturer's protocol with a cutoff titer at 1:64 was followed: $25 \mu \mathrm{L}$ latex agglutination buffer was first introduced to each well of a U-shaped 96-well microtitration plate; sera were diluted serially, starting with 1:8 dilution and then twofold dilutions, and the final $25 \mu \mathrm{L}$ was discarded; then $25 \mu \mathrm{L}$ of $T$. gondii antigen-coated 
latex beads were added to each well. The plate was incubated at room temperature overnight. Antibody titers were determined by the last dilution where agglutination pattern could be read in comparison with the positive control.

\section{Statistical analyses}

During rodent trapping and processing, we collected a set of variables that could possibly explain the infection by T. gondii and cause intra or interspecific differences in prevalences. These variables are phylogeny (at family, genus, or species levels), sex, maturity (determined after external and internal observation of sexual organs), season of trapping (dry or wet), morphology, and habitat. Several standard body measurements were taken in the field laboratory: weight, head and body length, tail length, hind foot length, ear length, and skull length. A precise environmental description of each trapping site was recorded in the field; the variable habitat refers here to a global classification of the landscape from wild to anthropized biotopes, coded as follows: forests (1), fields at the edge of forests (2), dry fields (3), wet rice fields (4), and domestic areas (5) (in proximity to human settlements, in houses, villages, or cities). Each variable was first analyzed univariately to measure the relation with $T$. gondii prevalence through Spearman correlations for continuous variables and Fischer's exact test (or Pearson $\chi^{2}$ tests where appropriate) for proportions of categorical ones. Then we tried to model the relationship between $T$. gondii seroprevalence and these variables using generalized linear and nonlinear models with prevalence as the dependent variable; habitat, season, sex, and maturity as categorical variables and body measurements as continuous variables. These models with binomial error and a logistic link function have proved to be appropriate statistical tools to assess the influence of explanatory variables on infection (Crawley 1993).

\section{Results}

Four hundred sixty one rodents were collected during the field study, including 408 rats and mice (Muridae) and 53 squirrels (Sciuridae) with a total of 18 species (Table 1). Only two mice were trapped because of the large size of the cages used, which are not suitable for small-sized rodents. Most of the rodent species occurring in Thailand can be easily caught, whether they live in wild habitats or close to human settlements.

The overall prevalence of $T$. gondii infection in rodents was $4.6 \%$ ( 21 positive out of 461 tested). The number of seropositive animals for each species is significantly correlated with the number of animals tested $(0.901, p<0.05)$. All species with $>37$ animals tested were found positive for at least one individual (Table 1): Rattus tanezumi (7.1\%, 11/156), Rattus exulans $(1.3 \%, 1 / 79)$, Menetes berdmorei $(7.7 \%, 4 / 52)$, Maxomys surifer $(5.3 \%, 2 / 38)$, and Bandicota indica $(2.7 \%, 1 / 37)$. This attests the wide spectrum of potential mammalian hosts of toxoplasmosis. In addition, two Leopoldamys sabanus individuals were found positive from 16 captured $(12.5 \%)$, which is the highest prevalence in rats. All $R$. norvegicus individuals tested negative for T. gondii antibodies, even if a relatively high number of individuals (34) were screened. No positives were found from the 11 other species that were captured in low numbers, such as Bandicota savilei, Berylmys bowersi, Berylmys berdmorei, Leopoldamys edwardsi, Niviventer fulvescens, Rattus andamanensis,
Table 1. Prevalence of Toxoplasma gondi Antibodies IN Rodents Trapped in ThaILAND

\begin{tabular}{|c|c|c|}
\hline Species & $\begin{array}{c}\text { No. of } \\
\text { positive/ } \\
\text { tested (\%) }\end{array}$ & $\begin{array}{l}\text { Provinces } \\
\text { (see Fig. 1) }\end{array}$ \\
\hline \multicolumn{3}{|l|}{ Murinae } \\
\hline Bandicota indica & 1/37 (2.7) & $1,2,3,4,8,12$ \\
\hline Bandicota savilei & $0 / 11(0)$ & 1 \\
\hline $\begin{array}{l}\text { Berylmys } \\
\text { berdmorei }\end{array}$ & $0 / 4(0)$ & 2,3 \\
\hline Berylmys bowersi & $0 / 5(0)$ & 2,3 \\
\hline $\begin{array}{l}\text { Leopoldamys } \\
\text { edwardsi }\end{array}$ & $0 / 3(0)$ & 1,2 \\
\hline $\begin{array}{l}\text { Leopoldamys } \\
\text { sabanus }\end{array}$ & $2 / 16(12.5)$ & 3 \\
\hline Maxomys surifer & $2 / 38(5.3)$ & $2,3,5$ \\
\hline Mus cervicolor & $0 / 1(0)$ & 8 \\
\hline Mus cookie & $0 / 1(0)$ & 1 \\
\hline $\begin{array}{l}\text { Niviventer } \\
\text { fulvescens }\end{array}$ & $0 / 13(0)$ & 3,12 \\
\hline $\begin{array}{l}\text { Rattus } \\
\quad \text { andamanensis }\end{array}$ & $0 / 7(0)$ & 2,3 \\
\hline Rattus exulans & $1 / 79(1.3)$ & $1,2,3,5,6,7,8,10,11,12$ \\
\hline Rattus losea & $0 / 1(0)$ & 2 \\
\hline Rattus norvegicus & $0 / 34(0)$ & 8 \\
\hline Rattus tanezumi & $11 / 156(7.1)$ & $2,3,5,6,8,9,10,12,13$ \\
\hline Rattus tiomanicus & $0 / 2(0)$ & 13 \\
\hline Total Muridae & $17 / 408(4.2)$ & \\
\hline \multicolumn{3}{|l|}{ Sciuridae } \\
\hline Callosciurus sp. & $0 / 1(0)$ & 3 \\
\hline $\begin{array}{l}\text { Menetes } \\
\text { berdmorei }\end{array}$ & $4 / 52(7.7)$ & 3 \\
\hline Total Sciuridae & 4/53 (7.5) & \\
\hline Total & $21 / 461(4.6)$ & \\
\hline
\end{tabular}

Rattus losea, Rattus tiomanicus, Mus cervicolor, Mus cookii, and Callosciurus sp. For these species, the number of animals tested is not sufficient to conclude that they might not get involved in the transmission of $T$. gondii. Among positive animals, the highest titer (1:512) was found in B. indica and R. tanezumi.

The seroprevalence was higher in Sciuridae $(7.5 \%)$ than in Muridae $(4.2 \%)$, but not significantly different (two-tailed Fisher's exact test, $p=0.285, p>0.05)$. Female rodents also presented a higher seroprevalence $(5.7 \%)$ than males $(3.3 \%)$ but not significantly different (two-tailed Fisher's exact test, $p=0.265, p>0.05)$. This was also verified for the $156 R$. tanezumi tested (8.3\% for females and $5.7 \%$ for males), which showed no statistical significance $(p=0.755)$. Moreover, even if the prevalence of adult rodents (4.7\%) was nearly twice the prevalence of young rodents $(2.6 \%)$, the effect of maturity on infection could not be statistically attested (two-tailed Fisher's exact test, $p=1, p>0.05)$. Finally, there was no relation between seroprevalences and body measurements either standardized or not.

According to the habitat, the number of seropositive animals is significantly correlated to the number of animals tested (0.979, $p<0.05)$. However, according to the level of anthropization of each habitat, the seroprevalence is not correlated to the anthropization index (Fig. 2). The highest seroprevalences are either observed in the less anthropized areas (forests: $6.2 \%$, $8 / 130$ ) or in the highly anthropized ones, near human settlements (domestic areas: $4.5 \%, 12 / 269$ ). 


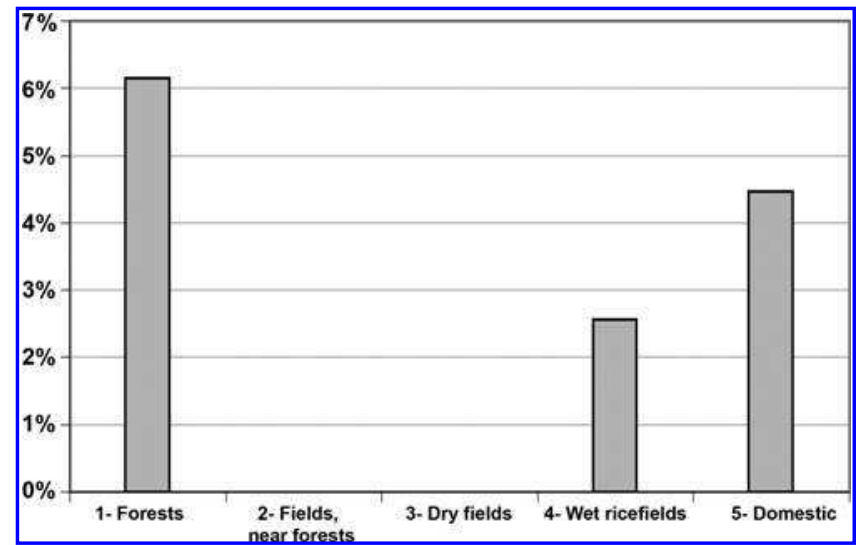

FIG. 2. Prevalence of Toxoplasma gondii in relation to a gradient of antrhopization in habitats.

From the multivariate analysis, only few models could be considered to estimate the presence or absence of infection. The best model (logit model) with two effects is obtained with the log-transformed weight and a three-way interaction between season, sex, and maturity $(p<0.01)$. A one-effect model with the three-way interaction between season, sex, and maturity is also relevant to predict infection $(p<0.005)$. However, only categorical variables (maturity, sex, and season) entered at $p<0.001$, whereas all continuous variables did not enter the model. Therefore, the model obtained is not robust and presents high deviance corresponding to overdispersion (residual deviance/residual $\mathrm{df}=0.37$ ).

\section{Discussion}

To compare our results with other investigations on T. gondii in rodents, we analyzed the review by Dubey and Frenkel (1998) and completed the available information with more recent papers (Supplemental Data, available online at www.liebertonline.com). In this review, only three species have been described in Thailand, namely $R$. norvegicus (the urban brown rat), $R$. rattus (the black rat), and Rattus exulans (the Polynesian rat). $R$. norvegicus and $R$. rattus have a worldwide distribution and have been frequently studied in several countries, whereas there is only less information on $R$. exulans present from mainland Asia to New Guinea and the Pacific region (Marshall 1988, Aplin et al. 2003). We could find out further research papers investigating the presence of $T$. gondii in rats, also known to occur in Thailand. Four studies have tested $R$. norvegicus (Lubroth et al. 1983, Salibay and Claveria 2005, Dubey et al. 2006, Kijlstra et al. 2008) and three studies have examined a fourth species, Mus musculus, the house mouse (Lubroth et al. 1983, Kijlstra et al. 2008, Murphy et al. 2008). Most of these studies have detected the presence of antibodies to $T$. gondii using various serological tests or T. gondii DNA by molecular method (polymerase chain reaction). The use of different techniques makes a global comparison of results hazardous if we do not consider their variability of specificity and sensitivity. The dye test has been the first technique, developed in 1948, and the most used (Ferguson 2009). It has proved to be highly specific and sensitive (Dubey 2008) and was then considered as a reference to evaluate other methods. Investigations that used the dye test have shown the highest prevalences in $R$. norvegicus $(12.8 \%$, $310 / 2426)$, then $R$. rattus $(8.3 \%, 78 / 936)$ and $R$. exulans $(3.8 \%$, $19 / 505)$. When compiling all serological results, rates are slightly higher for every species: $R$. norvegicus $(15.6 \%, 699 /$ $4482), R$. rattus $(12.2 \%, 169 / 1390)$, and $R$. exulans $(3.8 \%, 19 /$ $505)$, and a very high prevalence was shown for $M$. musculus $(60.0 \%, 12 / 20)$ in a single study by indirect immunofluorescent test. Recent studies have used polymerase chain reaction in The Netherlands and the United Kingdom, demonstrating a very high prevalence in $M$. musculus $(51.9 \%, 120 / 231)$ and lower in $R$. norvegicus $(10.3 \%, 4 / 39)$ (Kijlstra et al. 2008,



FIG. 3. Worldwide prevalence of T. gondii in Rattus norvegicus. 
Murphy et al. 2008). Despite the heterogeneity of these summarized data, results from serology and molecular diagnostic are relatively concordant.

This literature review also reveals a limited geographical range of T. gondii in M. musculus, R. norvegicus, and R. rattus, despite the worldwide distribution of these three rodent species. Indeed, the map of the worldwide prevalence of T. gondii in R. norvegicus shows a biased image of the infection, with the highest prevalences in North America, western Europe, and Egypt (Fig. 3). For the four species that we have selected, most of investigations have been conducted in developed countries located in the northern hemisphere (except Australia) where toxoplasmosis is a concern for human health and considered during pregnancy. There are no data from Africa, except from Egypt (Rifaat et al. 1971) and another regional study (de Roever-Bonnet 1972), no data from East and Southeast Asia, except the Philippines (Salibay and Claveria 2005) and Japan (Dubey and Frenkel 1998), and no data from South America.

These four species known in Thailand and cited in the literature are also the most common rodent species, living close to humans and potentially depending on humans as commensal. The high $T$. gondii prevalences reported in these species reflect their implication in a transmission cycle close to humans. Contrary to other investigations on rodents, our survey with no positive $R$. norvegicus questions its implication in the transmission of $T$. gondii in Bangkok metropolitan area where it lives. On one hand, the high prevalence $(15.5 \%)$ reported in the literature suggests that we might have missed positive animals or endemic areas. On the other hand, we can assess that $R$. norvegicus has possibly a minor role in the transmission cycle in Bangkok metropolitan area. Indeed, this species occupies different spaces than the increasing number of cats and stray dogs, which are designated to be the main actors of this transmission (Jittapalapong et al. 2007).

Global prevalences reported in the literature for $R$. rattus $(12.2 \%)$ and $R$. exulans $(3.8 \%)$ are slightly higher than those observed in our study for R. tanezumi $(7.1 \%)$ and R. exulans $(1.3 \%)$. It is surprising to find low prevalences of $T$. gondii in R. exulans both in the literature and in our study, because this species exclusively lives inside and around houses and can share its biotope with domestic cats, which are susceptible to shed oocysts in their feces and thus can infect rats. However, despite a low prevalence, R. exulans has an important role in the transmission cycle by maintaining parasites close to humans. $R$. rattus cited in these articles can refer to different species because it is now considered as a species group including an Oceanian or European type referred as R. rattus and an Asian type referred as $R$. tanezumi (Musser and Carleton 2005). Indeed, the complexity of this species group taxonomy makes hazardous any comparison of our results with other investigations.

Therefore, wild species described in Thailand have never been investigated and their importance in the transmission of $T$. gondii was not considered. Even if they do not live in contact with humans, Leopoldamys spp., Maxomys spp., and Menetes spp. may play a major role in maintaining tachyzoites and bradizoites in forested ecosystems and increasing the probability of infection of wild and domestic felids. This consideration is reinforced by the importance of the species of these three genera in wild habitats where other mammal species have become rare under a high hunting pressure in non- protected areas in Thailand. Further, it was unexpected to find such high prevalences in wild rodents, when considering the rarity of wild felids in Thai forests, which may theoretically result in a low circulation of oocysts. This questions the exclusive role of felids in hosting the sexual part of the life cycle of $T$. gondii. According to the International Union for Conservation of Nature and Natural Resources Red List of Threatened Species, only two species of wild felids are common in Thailand: Prionailurus bengalensis (leopard cat) and Felis chaus (jungle cat). Other felid species are now threatened or extinct. This assessment suggests that the sexual part of the life cycle of $T$. gondii might also be hosted by other carnivores considering their diversity and relative importance in the ecosystems, even if it has never been demonstrated in any of the countries. Common species are limited to one mongoose (Herpestidae): Herpestes javanicus (small Asian mongoose); two mustelids: Martes flavigula (Yellow-throated Marten) and Melogale personata (Burmese Ferret-badger); and a few viverrids including Paradoxurus hermaphroditus (common palm civet), Paguma larvata (masked palm civet), and Viverricula indica (small Indian civet). Further investigations should be conducted to verify these observations.

Finally, our results attest the low specificity of T. gondii, which can potentially infect any murine rodent species, whatever their sex, age, or morphology. Differences in prevalences related to sex and maturity are not clearly observed and may vary from one species to another according to specific social or feeding behavior, which can determine the exposure to the parasite. Nevertheless, the prevalence measured in young rodents $(2.6 \%)$, which is more than half the prevalence in adults $(4.7 \%)$, is relatively high when considering that youngest have less chance to get infected by free oocysts, as they are fed by their mothers. These high levels of infection may confirm a role for vertical transmission in maintaining infections within rodent populations, as it was demonstrated experimentally in M. musculus and Apodemus sylvaticus (Owen and Trees 1998). However, it seems that the efficiency of this vertical transmission is less in wild rodents than in experimental condition using captive-bred mice, with $82.7 \%$ $(n=83)$ and $85.0 \%(n=207)$ in pups, respectively. Further, high prevalences are observed in different habitats and suggest the existence of two cycles of transmission, a wild sylvatic cycle in forested habitats and a domestic cycle within human settlements, which might be rarely connected. This hypothesis should be better supported by molecular data. Rodents as well as nonrodent species may serve as such intermediate hosts and accidentally bring parasites horizontally from wild to highly anthropized biotopes or vice versa. Although rodent distribution is generally delimited in space by different biotopes, a few species such as $R$. tanezumi can inhabit a variety of biotopes. We trapped this species, also known as the Asian black rat, in the roof of houses in villages, gardens, ricefields, and also secondary forests. If we consider its high prevalence (7.1\%) compared with other species, we can conclude that $R$. tanezumi is a main actor of a horizontal transmission between biotopes.

Finally, T. gondii prevalence in rodents is influenced by environmental conditions that determine particularly the food and shelter availability and therefore the abundance and distribution of rodents and their predators (Meerburg et al. 2009). Indeed, rodent species have a high capacity for adaptation to rapid environmental changes. Rodents are usually 
the first mammals to invade deforested areas or agricultural fields, benefiting from a high reproductive potential and a short period of maturation (Aplin et al. 2003). The deterioration of biotopes consequently contributes to a horizontal transmission of toxoplasmosis by bringing healthy populations in new spaces where other wild mammals may have previously occurred and potentially spread oocysts.

In addition, the consumption of infected rats may increase the risk of a direct transmission from rats to humans, as it has been postulated for some populations in Nigeria with a significantly higher prevalence for those handling or eating rats (Olusi et al. 1994, Dubey and Frenkel 1998, Uneke et al. 2007). In Thailand, some rural populations also hunt wild rats as food and may be consequently exposed to infection by T. gondii. The transmission can occur by ingestion of blood when handling dead animals or when preparing them before cooking. Proper hygiene is recommended to avoid any contamination of food.

\section{Acknowledgments}

Laboratory work was conducted at the Department of Parasitology, Faculty of Veterinary Medicine, Kasetsart University in Thailand. The authors thank Kasetsart University Research Development Institution (KURDI) for partial funding. Field work was part of the "Eco-epidemiology of Hantaviroses in Thailand" (ANR, Program 00121 05) and the "CERoPath project" (Community ecology of rodents and their pathogens in Southeast Asia: effects of biodiversity changes and implications in health ecology/ANR 07 BDIV 012) funded by the French National Agency for Research. The authors particularly thank all those who have helped them in the field and the anonymous reviewers for insightful remarks.

\section{Disclosure Statement}

No competing financial interests exist.

\section{References}

Aplin, KP, Brown, PR, Jacob, J, Krebs, CJ, Singleton, GR. Field Methods for Rodent Studies in Asia and the Indo-Pacific. Canberra: Australian Center for International Agricultural Research, 2003.

Askins, R. Family Sciuridae: squirrels. In: Lekagul, B, Mc Neely, JA, eds. Mammals of Thailand. Bangkok: Association for the Conservation of Wildlife, 1988:337-387.

Carleton, MD, Musser, GG. Superfamily Muroidea. In: Wilson, DE, Reeder, DM, eds. Mammal Species of the World: A Taxonomic and Geographic Reference. Baltimore: The Johns Hopkins University Press, 2005:2142.

Corbet, GB, Hill, JE. Mammals of the Indomalayan Region: A Systematic Review. London and Oxford: Natural History Museum Publications and Oxford University Press, 1992.

Crawley, MJ. GLIM for Ecologists. Oxford: Blackwell Science, 1993.

Dabritz, HA, Miller, MA, Gardner, IA, Packham, AE, et al. Risk factors for Toxoplasma gondii infection in wild rodents from central coastal California and a review of T. gondii prevalence in rodents. J Parasitol 2008; 94:675-683.

de Roever-Bonnet, H. Toxoplasmosis in tropical Africa. Trop Geogr Med 1972; 24:7-13. de Thoisy, B, Demar, M, Aznar, C, Carme, B. Ecologic correlates of Toxoplasma gondii exposure in free-ranging neotropical mammals. J Wildl Dis 2003; 39:456-459.

Dubey, JP. The history of Toxoplasma gondii-the first 100 years. J Eukaryot Microbiol 2008; 55:467-475.

Dubey, JP, Bhaiyat, MI, Macpherson, CNL, de Allie, C, et al. Prevalence of Toxoplasma gondii in rats (Rattus norvegicus) in Grenada, West Indies. J Parasitol 2006; 92:1107-1108.

Dubey, JP, Frenkel, JK. Toxoplasmosis of rats: a review, with considerations of their value as an animal model and their possible role in epidemiology. Vet Parasitol 1998; 77:1-32.

Ferguson, DJP. Toxoplasma gondii: 1908-2008, homage to Nicolle, Manceaux and Splendore. Mem Inst Oswaldo Cruz 2009; 104:133-148.

Jittapalapong, S, Nimsupan, B, Pinyopanuwat, N, Chimnoi, W, et al. Seroprevalence of Toxoplasma gondii antibodies in stray cats and dogs in the Bangkok metropolitan area, Thailand. Vet Parasitol 2007; 145:138-141.

Jittapalapong, S, Sangvaranond, A, Pinyopanuwat, N, Chimnoi, W, et al. Seroprevalence of Toxoplasma gondii infection in domestic goats in Satun Province, Thailand. Vet Parasitol 2005; 127:17-22.

Kijlstra, A, Meerburg, B, Cornelissen, J, De Craeye, S, et al. The role of rodents and shrews in the transmission of Toxoplasma gondii to pigs. Vet Parasitol 2008; 156:183-190.

Kim, K, Weiss, LM. Toxoplasma: the next 100 years. Microbes Infect 2008; 10:978-984.

Lubroth, J-S, Dreesen, DW, Ridenhour, RA. The role of rodents and other wildlife in the epidemiology of swine toxoplasmosis. Prev Vet Med 1983; 1:169-178.

Marshall, JT. Family Muridae: rats and mice. In: Lekagul, B, Mc Neely, JA, eds. Mammals of Thailand. Bangkok: Association for the Conservation of Wildlife, 1988:397-487.

Maruyama, S, Boonmar, S, Morita, Y, Sakai, T, et al. Seroprevalence of Bartonella henselae and Toxoplasma gondii among healthy individuals in Thailand. J Vet Med Sci 2000; 62:635-637.

Mazumder, P, Chuang, HY, Wentz, MW, Wiedbrauk, DL. Latex agglutination test for detection of antibodies to Toxoplasma gondii. J Clin Microbiol 1988; 26:2444-2446.

Meerburg, BG, Singleton, GR, Kijlstra, A. Rodent-borne diseases and their risks for public health. Crit Rev Microbiol 2009; 35:221-270.

Mills, JN, Childs, JE, Ksiazek, TG, Peters, CJ, Velleca, WM. Methods for Trapping and Sampling Small Mammals for Virologic Testing. Atlanta: U.S. Department of Health and Human Services-Centers for Disease Control and Prevention, 1995.

Murphy, RG, Williams, RH, Hughes, JM, Hide, G, et al. The urban house mouse (Mus domesticus) as a reservoir of infection for the human parasite Toxoplasma gondii: an unrecognised public health issue? Int J Environ Health Res 2008; 18: 177-185.

Nicolle, C, Manceaux, L. Sur une infection à corps de Leishman (ou organismes voisins) du gundi. C R Acad Sci Hebd Seances Acad Sci 1908; 147:763-766.

Olusi, T, Ajaya, J, Makinde, A. Antibodies to Toxoplasma gondii in a rat-eating population on Benue State, Nigeria. Ann Trop Med Parasitol 1994; 88:217-218.

Owen, MR, Trees, AJ. Vertical transmission of Toxoplasma gondii from chronically infected house (Mus musculus) and field (Apodemus sylvaticus) mice determined by polymerase chain reaction. Parasitology 1998; 116:299-304.

Rifaat, MA, Mahdi, AH, Arafa, MS, Nasr, NT, Sadek, MS. Isolation of Toxoplasma from Rattus norvegicus in Egypt. Trans R Soc Trop Med Hyg 1971; 65:788-789. 
Salibay, CC, Claveria, FG. Serologic detection of Toxoplasma gondii infection in Rattus spp collected from three different sites in Dasmariñas, Cavite, Philippines. Southeast Asian J Trop Med Public Health 2005; 36:46-49.

Splendore, A. Un nuovo parassita deconigli incontrato nelle lesioni anatomiche d'une malattia che ricorda in molti punti il Kala-azar dell'uomo. Nota preliminare pel. Rev Soc Sci Sao Paulo 1908; 3:109-112.

Tenter, AM, Heckeroth, AR, Weiss, LM. Toxoplasma gondii: from animals to humans. Int J Parasitol 2000; 30:1217-1258.

Thiangtum, K, Nimsuphun, B, Pinyopanuwat, N, Chimnoi, W, et al. Seroprevalence of Toxoplasma gondii in captive felids in Thailand. Vet Parasitol 2006; 136:351-355.

Thiptara, A, Kongkaew, W, Bilmad, U, Bhumibhamon, T, Anan, S. Toxoplasmosis in piglets. Ann N Y Acad Sci 2006; 1081: 336-338.

Tilahun, W, Arnaud, LF, Tefera, S, Henk, G, et al. Evaluation of the Eiken latex agglutination test for anti-Toxoplasma antibodies and seroprevalence of Toxoplasma infection among factory workers in Addis Ababa, Ethiopia. Trans R Soc Trop Med Hyg 1998; 92:401-403.
Tuntasuvan, D, Mohkaew, K, Dubey, JP. Seroprevalence of Toxoplasma gondii in elephants (Elephus maximus indicus) in Thailand. J Parasitol 2001; 87:229-230.

Uneke, C, Duhlinska, D, Ngwu, B, Njoku, M. Seroprevalence of Toxoplasma gondii infection in Kwal, a rural distriction of Plateau-Nigeria. Afr J Med Med Sci 2007; 36:109-113.

Wallace, GD, Marshall, L, Marshall, MAC. Cats, rats, and toxoplasmosis on a small Pacific island. Am. J. Epidemiol 1972; 95:475-482.

Address correspondence to: Vincent Herbreteau

CIRAD

UR Animal et Gestion Intégrée des Risques (AGIRs)

Campus International de Baillarguet Maison de la télédétection 500, rue Jean-François Breton 34093 Montpellier Cedex 5

France

E-mail: vincent.herbreteau@teledetection.fr 
